\title{
Advanced glycation: an important pathological event in diabetic and age related ocular disease
}

\author{
Alan W Stitt
}

The formation of advanced glycation end products (AGEs) is a key pathophysiological event with links to a range of important human diseases. It is now clear that AGEs may act as mediators, not only of diabetic complications ${ }^{12}$ but also of widespread age related pathology such as Alzheimer's disease, ${ }^{3}$ decreased skin elasticity, ${ }^{45}$ male erectile dysfunction, ${ }^{67}$ pulmonary fibrosis, ${ }^{8}$ and atherosclerosis. ${ }^{9}{ }^{10}$ Since many cells and tissues of the eye are profoundly influenced by both diabetes and ageing, it is fitting that advanced glycation is now receiving considerable attention as a possible modulator in important visual disorders. An increasing number of reports confirm widespread AGE accumulation at sites of known ocular pathology and demonstrate how these products mediate crosslinking of long lived molecules in the eye. Such studies also underscore the putative pathophysiological role of advanced glycation in ocular cell dysfunction in vitro and in vivo.

This article reviews some of the important effects that advanced glycation has on ocular tissues and the role that AGEs, and their specific receptors, have in the initiation and progression of sight threatening disorders such as diabetic retinopathy, glaucoma, cataract formation, and age related macular degeneration (AMD). This review also considers pharmacological strategies to prevent or neutralise the effects of AGEs and the recent development of potential therapies for AGE induced disease processes.

\section{Biochemistry of AGE formation in biological systems}

AGEs form via non-enzymatic condensation reactions between reducing sugars and $\varepsilon$-amino groups or N-terminal groups. These glycation modifications occur preferentially on lysine and arginine amino acids, although they can occur on free amine containing lipids and DNA and proceed spontaneously via a complex series of chemical rearrangements to yield reactive products with varying crosslinking, pigmentation, and fluorescence properties. ${ }^{11}$ Non-enzymatic glycation reactions were first described around the turn of the century by Louis Camille Maillard who predicted that they could have an important impact on medicine and coined the term "Maillard reaction." 12 Unfortunately Maillard chemistry was not recognised by medical researchers until after its "rediscovery" by food scientists nearly 50 years later, who realised that the products of non-enzymatic glycation were important in food flavour, aroma, and nutritional bioavailability. ${ }^{13}$ Only recently has the full pathophysiological significance of this ubiquitous reaction emerged as a field of study in medicine in its own right.

In biological systems, reducing sugars react with free amino groups to form Schiff base adducts and Amadori products such as fructose-lysine. It is worth noting that glucose is among the least reactive sugars within biological systems, while other sugars and dicarbonyls, many of which are located intracellularly, such as glucose-6phosphate and glyceraldehyde-3-phosphate, are much more reactive and participate in glycation reactions at a proportionally faster $\operatorname{rate}^{14}$ (Fig 1). In any case, the chemically unstable Schiff bases and Amadori products are freely reversible and therefore exist in an equilibrium which is proportional to the amount of free sugar. An understanding of non-enzymatic glycation kinetics in vivo led to the conceptualisation of glycosylated haemoglobin and to the eventual development of the clinical assays which measure Amadori product formation on the $\mathrm{HbA}_{1}$ amino terminal valine of the $\beta$ chain over a 28 day period $\left(\mathrm{HbA}_{1 \mathrm{c}}\right)^{15}$ thereby providing diabetologists with a useful index of glycaemic control. ${ }^{16}$ Significantly, the levels of Amadori products in diabetic patients are usually no more than twofold to threefold higher than in their non-diabetic counterparts, which is an indication of the freely reversible nature of these products and the equilibrium which is always reached between modified and non-modified forms of a protein. Therefore, Amadori modifications do not accumulate indefinitely on long lived macromolecules and there is no correlation between the formation of these adducts on tissues and diabetic complications. ${ }^{17}$

Non-enzymatic glycation reactions culminate in the formation of AGEs. The majority of these products are formed from a vast range of precursor molecules, the variable chemical nature of which contributes to AGE heterogeneity. For example, the Amadori intermediate can undergo metal catalysed oxidative reactions and gives rise to irreversible "glycoxidation" products such as $\mathrm{N}-\varepsilon-$

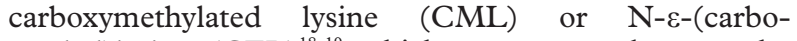
xyethyl)lysine (CEL) ${ }^{18} 19$ which can accumulate on the substrate to which they are attached and/or lead to the formation of highly reactive dicarbonyl compounds. Dicarbonyls such as 1-, 3-, or 4-deoxyglucosones, glyoxal, and methylglyoxal are highly reactive intermediates, which will in turn react with proteins and propagate intramolecular or intermolecular crosslink formation ${ }^{20}$ (Fig 1). These pathways are an equally important source of AGEs within the cell and, because they arise from highly reactive "AGE intermediates," they can occur very rapidly. ${ }^{20}{ }^{21}$ The chemical nature of these biologically important AGEs, as they occur naturally in vivo, is largely unknown owing to their heterogeneous and unstable nature; nevertheless, there is a growing population of structurally defined AGE adducts such as pyrraline, ${ }^{22}$ pentosidine, ${ }^{23} \mathrm{CML},{ }^{18}$ and crossline $^{24}$ (Fig 2) which have been found to be elevated in diabetic tissues. ${ }^{25} 26$

While AGEs form in vivo, it is now clear that extrinsically formed moieties can also have a significant role in our advanced glycation burden. Tobacco curing is essentially a Maillard "browning" reaction and combustion of these adducts during smoking can release reactive, 


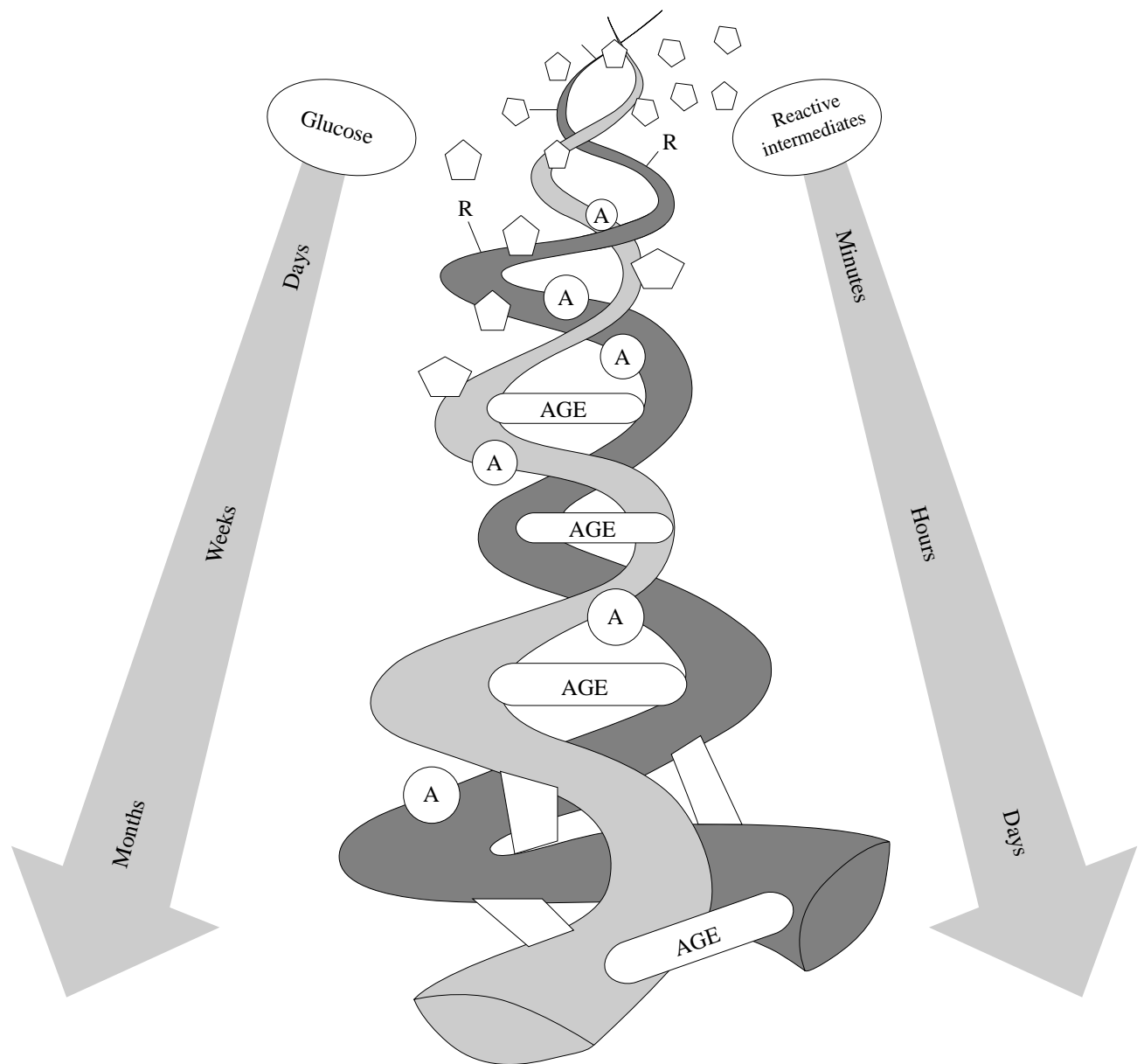

Figure 1 Schematic diagram illustrating the course of AGE formation on a hypothetical fibrilar protein. Open chain sugars or glycolytic intermediates ( () ) react with amino groups $(R)$ to form Schiff bases and Amadori products $(A)$ and eventually AGEs. Glucose may take several weeks to culminate in AGE formation leading to irreversible crosslink formation between protein fibrils or oxidative products. Reactive glycolytic intermediates such as methylglyoxal or 3-deoxyglucosone take much less time to form AGEs. Such AGE crosslinks can have a serious influence on protein structure and function.

toxic glycation products (or glycotoxins) which enter the blood stream and because of their crosslinking properties become fixed in tissues. ${ }^{27}{ }^{28}$ Recent evidence also suggests that many foods can form very high AGE levels during cooking which, upon digestion, release reactive peptide species into the circulation with an ability to form covalent crosslinks. ${ }^{29}{ }^{30}$ In the presence of normal renal function most of these reactive species are rapidly cleared from the circulation; however, in individuals with compromised renal clearance, these glycotoxins may remain within the circulation for prolonged periods of time ${ }^{29}$ with crosslinking potential and resultant pathophysiological consequences.

\section{Role of AGEs in cellular systems}

Since AGEs are constantly forming under physiological conditions complex receptor systems have evolved to remove senescent, glycation modified molecules and/or degrade existing AGE crosslinks from tissues thereby limiting their deleterious effects. Such receptors play a critical part in AGE related biology and the pathology associated with diabetes and ageing. ${ }^{12}$ Several AGE binding molecules have been described and it has been established that many of the adverse effects caused by advanced glycation are mediated via AGE receptors such as RAGE, ${ }^{31}$ the AGE receptor complex (AGE-RC), ${ }^{32}$ and the type I and II scavenger receptor. ${ }^{34}$ The precise role of these receptors in instigating pathological events is currently ill defined and it remains controversial if some or all AGE receptors serve to promote or limit AGE mediated cell and tissue dysfunction. The elucidation of AGE receptor modulatory roles and signal transduction pathways are areas of intensive investigation and recent evidence suggests that AGE receptor binding can initiate important signalling pathways involving activation of protein kinase $C,{ }^{35}{ }^{36}$ tyrosine phosphorylation of Janus kinase (JAK)/signal transducers and activators of transcription (STAT), ${ }^{37}$ recruitment of phosphotidylinositol $3^{1}$ kinase to Ras, ${ }^{38}$ and induction of oxidative stress cascades which culminate in $\mathrm{NF \kappa B}$ and AP-1 transcription. ${ }^{39} 40$

AGEs can initiate a wide range of abnormal responses in cells and tissues such as inappropriate expression of growth factors, alterations in growth dynamics, accumulation of extracellular matrix, promotion of vasoregulatory dysfunction, and initiation of death pathways. ${ }^{129}$ Many of these responses are mediated through receptor mediated pathways ${ }^{1}$ and the pathogenic influence of high AGE levels is well illustrated through several studies by Vlassara et al in which normoglycaemic animals were chronically injected with preformed AGE albumin. Such animals developed high concentrations of crosslinked collagen in their vascular walls with accompanying hyperpermeability and defective vasodilatory responses to acetylcholine and nitroglycerin. ${ }^{41}$ Predictably, these effects were significantly reversed by the pharmacological AGE inhibitor aminoguanidine. ${ }^{41}$ AGE infusion of normoglycaemic rats also upregulated glomerular collagen IV, laminin $\beta 1$, and transforming growth factor $\beta I$ mRNA levels leading to renal hypertrophy 
<smiles>OCC(O)C(O)C(O)c1c[n+]([125I])cc2c1C(O)C(O)CN2[Nb]</smiles>

Crosslines<smiles>[R]n1c(CO)ccc1C(=O)O</smiles>

Pyrraline

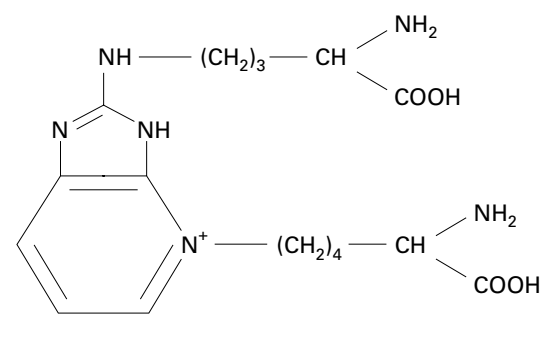

Pentosidine

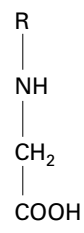

CML after only 4 weeks. ${ }^{42}$ Longer infusion ( 4 months) caused marked glomerulosclerosis and albuminuria ${ }^{43}$ correlating with changes observed in long term diabetic rats.

These various AGE modifications have serious consequences for macromolecular function, especially in the case of $\mathrm{DNA}^{44}$ important structural proteins, ${ }^{45}{ }^{46}$ enzymes, ${ }^{47}$ and growth factors/hormones. ${ }^{48} 49$ Indeed, such effects, in combination with inappropriate receptor interactions can initiate a wide range of deleterious cellular responses, especially within the context of diabetes and ageing where accumulative levels of AGE are highest and renal function may be impaired.

\section{AGEs in ocular tissues}

LENS

Cataract formation is the leading cause of visual impairment across the world. ${ }^{50}$ While there are many causes of lens opacity, ageing is by far the major risk factor ${ }^{5152}$ with excessive ultraviolet light exposure ${ }^{53}$ and associated free radical damage of crystallins ${ }^{54}$ being the key pathogenic factor. The role of Maillard reactions in cataract formation has also been extensively studied in both the aged and diabetic lens where AGEs of various derivations and molecular structures have been shown to be markedly elevated..$^{5-58}$ Glycation generates significant age related alterations in lens fibre membrane integrity and tertiary structure of lens proteins. This leads to aggregation and covalent crosslinking of lens crystallins which, irrespective of cataract formation, can result in reduced deformability with accompanying presbyopia..$^{59}$ The action of highly reactive dicarbonyl compounds such as glyoxal and methylglyoxal is enhanced in diabetes and ageing, leading to AGE crosslinks on $\alpha$ crystallins with resultant loss of chaperone activity, increased $\alpha \beta$ crystallin content and dense aggregate formation. ${ }^{60-62}$

The action of metal catalysed, Fenton reactions which culminate in hydroxyl radical generation may have major pathogenic significance in cataract formation, especially in diabetics where there is a significant accumulation of copper in the lens cells. ${ }^{63}{ }^{64}$ Recent evidence suggests that a close association exists between advanced glycation, metal ions, and generation of free radicals during age related cataract formation, where AGE formation on crystallins leads to binding of redox active copper which in turn catalyses ascorbate oxidation. ${ }^{65}$

As stated previously, tobacco products may be a rich source of reactive glycation products, capable of promoting AGE formation in vivo. ${ }^{27}$ In a study of cataractous lenses there were significantly higher levels of immunoreactive AGEs in those patients with a history of smoking ${ }^{28}$ (Fig 3). Smoking releases highly reactive gas phase oxidants into the blood stream ${ }^{66}$ and is a clear risk factor for cataract formation. ${ }^{67}$ It is now evident that cigarette smoke mediated AGE formation may act in concert with heavy metal deposition and oxidative stress to precipitate cataract formation.

CORNEA

The Maillard reaction has a significant role in altering corneal biochemistry during diabetes and ageing. Diabetic keratopathy ${ }^{68}$ is manifested by thickening of the stroma and basement membranes, recurrent erosions, corneal oedema, and morphological alterations in the epithelial and endothelial layers. ${ }^{68}$ Such alterations in the human diabetic cornea are accompanied by decreased protein stability in the stroma and basal laminae and increased immunoreactive AGEs which have been partially characterised as pentosidine ${ }^{69}$ and CML. ${ }^{70}$ Bowman's membrane is heavily glycated in diabetic patients ${ }^{70}$ while in vitro AGE modified substrates can significantly reduce corneal epithelial cell adhesion and spreading, ${ }^{70}$ possibly by disruption of integrin/non-integrin receptor-matrix interactions which has obvious pathogenic implications for recurrent erosions.

AGEs also accumulate in the ageing cornea ${ }^{71}{ }^{72}$ as they do in extracellular matrix proteins in other tissues. ${ }^{45}$ Such age related crosslinking occurs largely on the collagen component of the cornea (stroma and lamina) and can be effectively reversed using aspirin-like analgesics which have defined antiglycation properties. ${ }^{73}$ Interestingly, it has been proposed that AGE mediated crosslinking could have benefits as a means for stiffening and strengthening the weakened cornea of patients with keratoconus. ${ }^{74}$ 

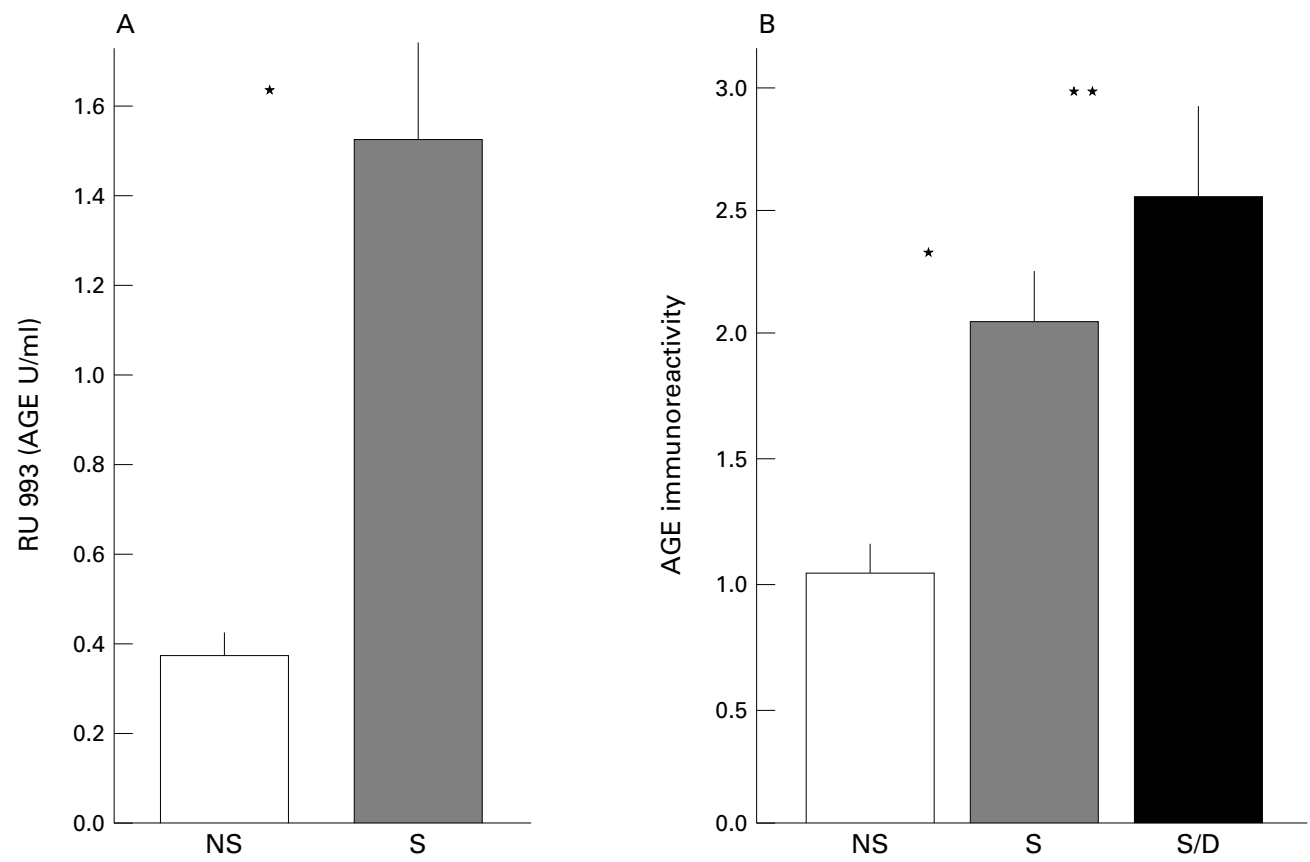

Figure 3 AGEs accumulate at high levels in the lens and coronary arteries of smokers. (A) The cataractous lenses of smokers $(S)$ and non-smokers (NS) were removed, the protein extracted and quantified for AGE immunoreactivity using a competitive AGE-ELISA. AGE levels were significantly higher in the lenses of smokers $\left({ }^{\star} p<0.0007\right)\left(N i c h o l l\right.$ et al $\left.{ }^{8}\right)$. (B) AGE immunoreactivity in the vascular walls of coronary arteries from smokers, non-smokers, and smokers with diabetes. AGEs deposited at higher levels in patients with a history of smoking tobacco products. Significantly, patients who had diabetes and also smoked had supraelevated levels in their coronary arteries $\left({ }^{\star} p<0.015 ;{ }^{\star} p<0.001\right)$.

VITREOUS

The vitreous gel is composed largely of a complex network of crosslinked collagen (type II,V/IX, and XI) fibrils and the hydrophilic glycosaminoglycan, hyaluronan. ${ }^{75}$ Disorders of the vitreous often manifest themselves as morphological changes to the collagen component within the cortical gel and age related vitreous degenerations are usually a direct result of dissociation of collagen and hyaluronan. ${ }^{76}$ Structural changes to the vitreous such as liquefaction and posterior vitreous detachment (PVD) are associated with ageing while in diabetics such changes occur earlier than in non-diabetics in a condition Sebag has called diabetic vitreopathy. ${ }^{77}$

The molecular basis of vitreous degeneration remains somewhat equivocal. ${ }^{77}$ In terms of advanced glycation mediated pathology, it has been demonstrated that glycation can induce abnormal crosslinks between vitreal collagen fibrils leading to dissociation from hyaluronan and resultant destabilisation of the gel structure. ${ }^{76}$ Moreover, AGEs have been described in human vitreous where they correlate with age and accumulate at an even higher level in diabetic patients. ${ }^{78}$ The significance of this has also been shown in bovine vitreous incubated ex vivo in high glucose conditions where immunoreactive AGEs formed on the vitreous collagen component and resulted in enhanced crosslinking of the fibrils - a process which could be significantly inhibited by the AGE inhibitor aminoguanidine. ${ }^{78}$

Sebag has described the pathogenesis of vitreous degeneration in diabetics as a process of "precocious senescence"79 and while other non-glycational physiological and biochemical processes contribute to vitreous degeneration it would appear that AGEs have an important role in diabetic and ageing vitreous dysfunction.

RETINA (DIABETIC RETINOPATHY)

In diabetes the retinal microvasculature becomes progressively dysfunctional in response to variable hyperglycaemia and in this progressive disease there is widespread loss of retinal pericytes and failure of endothelial cells, leading to capillary closure and retinal ischaemia.$^{80}$ In common with other vascular beds in the body, AGEs and/or late Amadori products have been localised to retinal vessels and neuroglia of diabetics. ${ }^{81-85}$ The precise part played by these adducts in the pathogenesis of diabetic retinopathy remains ill defined although experimental studies have demonstrated that AGEs may be responsible for retinal vascular lesions ${ }^{86} 87$ and that aminoguanidine can prevent this pathology. ${ }^{88}$ Interestingly, aminoguanidine does not prevent the initial phase of experimental diabetic retinopathy in rats ${ }^{89}$ although a secondary intervention study with this drug has been shown to retard disease progression. ${ }^{90}$ In diabetic rats, AGEs are not only localised to vascular basement membranes (BMs), but also appear to accumulate in the retinal pericytes after 8 months of diabetes $^{81}$ (Fig 4). Moreover, when non-diabetic animals are infused with preformed AGE albumin, these adducts accumulate around and within the pericytes, co-localise with AGE receptors, induce BM thickening, and cause breakdown of the inner blood-retinal barrier. ${ }^{81} 8791$ In clinical studies it has been reported that the levels of serum AGEs, and also the glycoxidation product CML, correlate with the degree of diabetic retinopathy. ${ }^{92} 93$

In vitro investigation of retinal vascular cells has provided important insights into the action of these adducts, their receptors, and how they contribute to tissue dysfunction in diabetes. Retinal vascular endothelial cells exposed to AGEs show abnormal endothelial nitric oxide synthase (eNOS) expression, which may account for some of the vasoregulatory abnormalities observed in the diabetic vasculature. ${ }^{94}$ Advanced glycation can mediate pathophysiological differentiation events (for example, calcification) in retinal pericytes ${ }^{95}$ and initiate abnormal growth responses in retinal vascular cells ${ }^{96}{ }^{97}$ which can be modulated, at least in part, by AGE receptors. In addition, vascular endothelial growth factor (VEGF), which at high levels is important for vascular incompetence and proliferation can be upregulated in many retinal cell types after exposure to AGEs, ${ }^{98-100}$ an effect exacerbated by low $\mathrm{PO}_{2}$ 

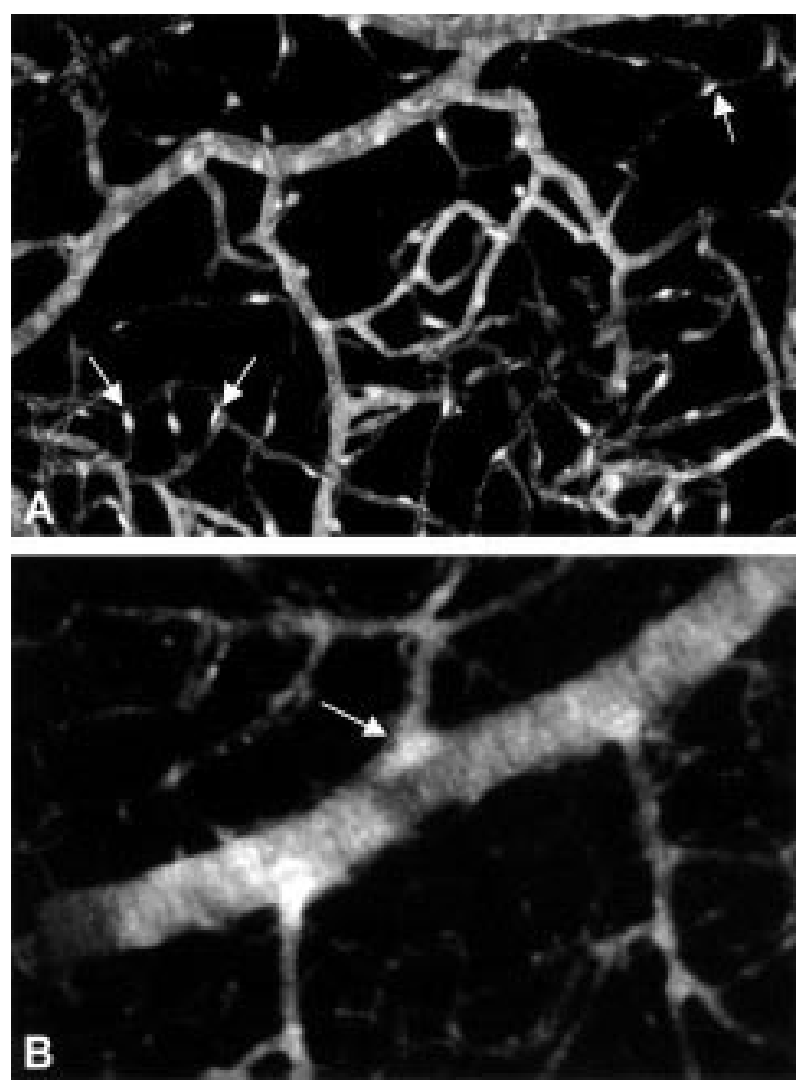

Figure 4 AGE immunoreactivity in diabetic and aged rats. (A) Trypsin digest of retinal vascular tree from an 8 month diabetic rat. $A G E$

immunoreactivity is marked in the arterioles and capillaries. The pericytes of the retinal capillary beds are hyperfluorescent indicating accumulation of AGEs (arrows). (B) AGE immunoreactivity in the retinal vasculature of a 28 month old, non-diabetic rat. The immunofluorescence pattern is different from that observed in the diabetic retina $(A)$ with $A G E$ localisation appearing confined to the vascular basement membranes of arteries, arterioles and, to a lesser extent, the capillaries. Note the bright fluorescence at arteriolar sphincters (arrow).

(hypoxic) conditions ${ }^{98}$ with clear implications for barrier dysfunction and disruption of vascular cell growth dynamics. More research is needed to determine AGE pathogenic influences on retinal vascular function, but it is clear that these products, whether as adducts on important serum derived proteins, as reactive intracellular intermediates or as accumulative extracellular matrix crosslinks have the potential to disrupt key signalling pathways with significant impact on cellular function. Future mechanistic in vitro and in vivo studies will help to establish the precise role of advanced glycation in diabetic retinopathy.

RETINA (AGE RELATED DYSFUNCTION)

A spectrum of age related changes in the retinal pigment epithelium (RPE) and underlying Bruch's membrane has been described clinically, ultrastructurally, and histopathologically. The most prominent of these changes, coinciding with the early stages of AMD, are extracellular deposits of drusen, basal laminar deposits (BLDs), and changes in the chemical composition, physical structure, and hydrodynamics of Bruch's membrane..$^{101} 102$ Such changes are thought to be important in the development of AMD. ${ }^{103}$ Drusen and BLDs form between Bruch's and the RPE ${ }^{102}$ and although the histopathological characteristics of the deposits are well documented, their precise chemical composition has only been partly resolved. BLD and drusen have deleterious effects on RPE structure and function and the accumulation of lipofuscin and undigested phagosomes in RPE cells with age has a direct influence on cellular function and outer retinal integrity. ${ }^{104}{ }^{105}$ Lipofuscin accumulation in RPE cells may reflect accelerated phagocytosis of defective rod outer segments and/or impaired degradation of engulfed photoreceptor remnants due to altered digestibility or failure of lysosomal activity. ${ }^{106}{ }^{107}$ Impaired RPE processing of shed photoreceptor outer segments is associated with drusen formation $^{108} 109$ although the precise pathogenesis is poorly understood.

There are growing links between advanced glycation and ageing changes at the outer retina. Recent reports suggest that AGEs accumulate in drusen and in Bruch's membrane with age and occur at a higher level in patients with AMD. ${ }^{10-113}$ Further evidence linking AGE accumulation to AMD can be surmised from the composition of drusen which contains lipids, apolipoprotein E, amyloid, and vitronectin $^{114} 115$ (proteins which are modified by Maillard chemistry during ageing). ${ }^{116-118}$ Advanced glycation is a feature of BM thickening and extracellular matrix dysfunction during diabetes and it is significant that Bruch's membrane is also known to thicken progressively in older patients and become less permeable. ${ }^{101} 119$

RPE cells are radically influenced by exposure to AGEs in vitro where they express abnormal levels of vascular endothelial growth factor (VEGF) and platelet derived growth factor B (PDGF-B). ${ }^{98} 112$ This may have a bearing on RPE cell function, maintenance of the choriocapillaris, and integrity of the $\mathrm{RPE} /$ photoreceptor complex. The accumulation of lipofuscin and reduction of lysosomal degradative capacity in RPE cells may reflect AGE formation and receptor mediated transport of these adducts to the lysosomal compartment (Fig 5). Significantly, intracellular sequestration of these highly reactive adducts can
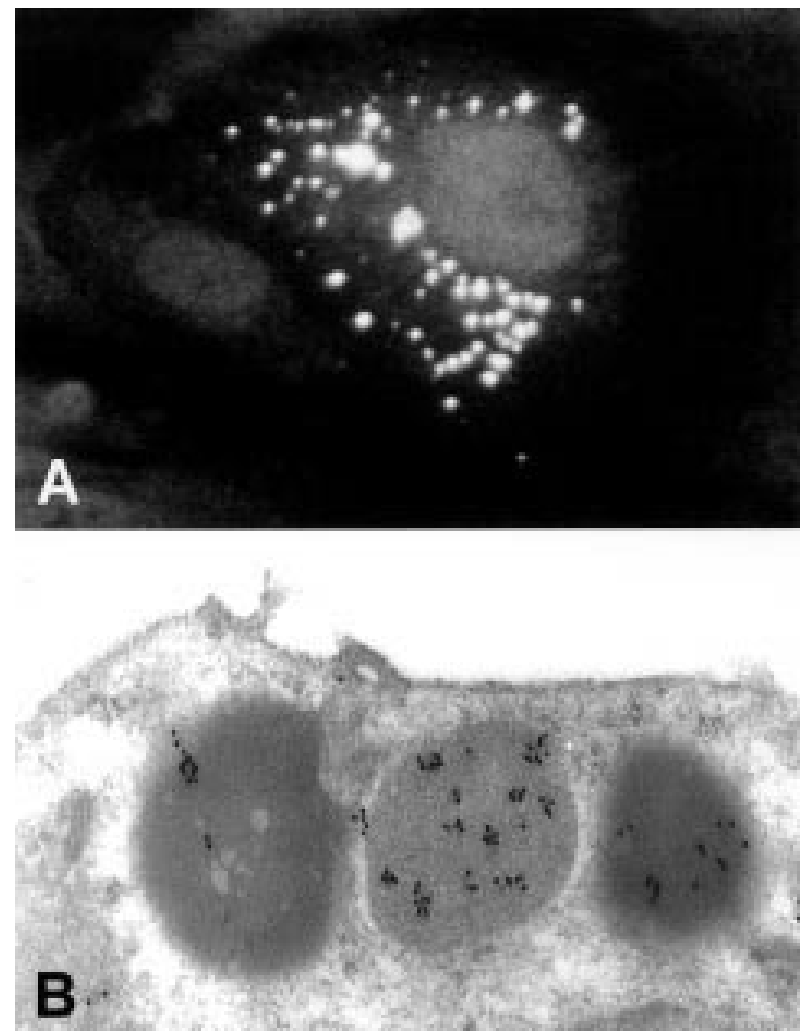

Figure 5 AGEs and $A G E$ receptor accumulation in lysosomes. (A) $A G E$ receptor component $(A G E-R 1)$ (see Stitt et al ${ }^{33}$ ) immunoreactivity in a human RPE cell which was exposed to $A G E$ albumin for 4 days before fixation. Note the hyperfluorescent areas in a perinuclear position-a distribution pattern which is indicative of RPE lysosomal compartments.

(B) AGE immunoreactivity in a glomerular epithelial cell from a diabetic dog. Note the high density of gold particles in the lysosomes which indicate $A G E$ accumulation in these organelles. 
markedly reduce lysosomal enzymatic activity in other epithelial cell types. ${ }^{120-122}$ Incomplete degradation of phagocytosed photoreceptor outer segments is linked to the formation of lipofuscin in RPE cells ${ }^{123}$ and it is notable that advanced glycation reactions appear to play an important part in the formation of age related intracellular fluorophores and lipofuscin granules in post-mitotic epithelial cells. $^{124}$

\section{OTHER OCULAR TISSUES}

Age related changes to retinal ganglion cells and the optic nerve head is a recognised phenomenon with an aetiological role in the pathogenesis of chronic open angle glaucoma. ${ }^{125}$ Since AGE adducts accumulate with age on many long lived macromolecules it is perhaps unsurprising that these products have been detected within the collagenous matrix of the lamina cribrosa where levels correlate with age. ${ }^{126}$ The lamina cribrosa has an important role in supporting the optic nerve axonal structure and the AGE mediated crosslinking of this matrix may reduce flexibility and perhaps induce age related axon damage which is characteristic of this degenerative glaucomatous disease. ${ }^{126}$ Indeed, inhibition of AGE formation in diabetic rats effectively prevented diabetes induced myelinated optic nerve atrophy. ${ }^{127}$

\section{Anti-AGE therapeutic strategies}

Prevention or amelioration of AGE mediated cell toxicity has been a key strategy in the prevention of diabetic complications and some age related pathology. To date there have been a range of approaches which seek to either prevent AGE formation, reduce AGE effects on cells, or even break established AGE crosslinks.

Amadori product formation is the basis of advanced glycation biochemistry because progression to protein crosslinks requires slow chemical rearrangement to create reactive intermediates before the formation of irreversible AGEs. An important pharmacological strategy for the inhibition of this process utilises the small nucleophilic hydrazine compound aminoguanidine, which is a potent inhibitor of AGE mediated crosslinking. ${ }^{128}$ This drug can prevent some diabetic vascular complications in experimental animals, ${ }^{88}{ }^{129-133}$ while clinical trials of aminoguanidine were shown to effectively reduce AGE-Hb while leaving $\mathrm{HbA}_{1 \mathrm{c}}$ unaffected. ${ }^{134}$ Such optimism has been tempered by the gradual realisation that aminoguanidine also inhibits a range of other important pathways, most notably generation of nitric oxide by eNOS, ${ }^{135}$ which may increase non-specific and unwanted side effects of the drug. Nevertheless, aminoguanidine and/or other related AGE inhibitors may eventually find a place in the management of diabetics or in individuals at risk of age related sequelae. Other AGE inhibiting drugs have been recently developed, such as the thiazolidine derivative OPB-9195, ${ }^{136}$ pyridoxamine, ${ }^{137}$ and 2,3 diaminophenazine (2,3 DAP). ${ }^{13}$

Prevention of AGEs interacting with their receptors or other body proteins is a valid therapeutic approach. The use of neutralising antibodies against glycated albumin has been shown to prevent $\mathrm{BM}$ thickening in diabetic $(\mathrm{db} / \mathrm{db})$ mice despite the fact that the antibodies did not alter the glycaemic status of the animals. ${ }^{87}$ Likewise, the use of the AGE binding properties of lysozyme has succeeded in reducing AGE levels in dialysate from diabetic patients with kidney disease $^{139}$ and presents a real possibility for reduction of toxic AGE groups in the body fluids of patients with renal failure. Furthermore, elucidation of AGE receptor signal transduction pathways may also offer intracellular strategies to control receptor mediated sequelae.

Recently, a novel therapeutic strategy has been to attack the AGE crosslinks formed in biological systems. This is an exciting approach since it would "break" pre-accumulated AGEs and subsequently allow clearance via the kidney. Such an AGE crosslink "breaker" prototype has been described to attack dicarbonyl derived crosslinks in vitro. ${ }^{140}$ There are now at least two such chemical agents which have the ability to reduce the tissue content of AGEs in experimental diabetes ${ }^{141}{ }^{142}$ reverse hyperglycaemia related arterial distensibility, ${ }^{136}$ and ameliorate age related myocardial stiffness. ${ }^{143}$

\section{Conclusion}

It is evident that AGEs may play a significant pathogenic part in diabetic complications and many age related disorders. The pathogenesis of such disorders are multifactorial and it is clear that advanced glycation, while perhaps having a significant role, is not the only processes leading to cell and tissue dysfunction. Nevertheless, key events in diabetes and ageing such as free radical generation and inappropriate activation of signalling molecules (for example, protein kinase $\mathrm{C}, \mathrm{NF} \kappa \mathrm{B}$ gene transcription) may have important links to or are secondary consequences of advanced glycation processes. It must also be stated that in many ageing ocular tissues the accumulation of AGEs may represent a function of the ageing process and their direct aetiological function needs to be directly and unequivocally proved. Whatever their place in the pathogenic hierarchy of ocular disease, AGEs may play an important part in diabetic retinopathy and cataract formation while their putative involvement in glaucoma, diabetic keratopathy, and $\mathrm{AMD}$ requires much more evaluation. As research intensifies into Maillard chemistry and the cellular and molecular consequences of advanced glycation, and as pharmacological intervention strategies evolve, we may be close to reducing some of the sight threatening complications affecting diabetic and older individuals.

The support of Fight for Sight (UK), Diabetes UK, The Juvenile Diabetes Foundation International, The National Lottery Charities Board, The Iris Fund, and The Wellcome Trust is gratefully acknowledged.

ALAN W STITT

Department of Ophthalmology, The Queen's University of Belfast, The Royal Victoria Hospital, Belfast BT12 6BA, Northern Ireland, UK

a.stitt@qub.ac.uk

1 Vlassara H, Bucala R, Striker L. Pathogenic effects of advanced glycosylation endproducts: biochemical, biologic, and clinical implications for diabetes and aging. Lab Invest 1994;70:138-51.

2 Stitt AW, Vlassara H. Advanced glycation endproducts: impact on diabetic complications. In: Betteridge DJ, ed. Current perspectives in diabetes. London: Martin Dunitz, 1999:67-92.

3 Munch G, Schinzel R, Loske C, et al. Alzheimer's disease-synergistic effects of glucose deficit, oxidative stress and advanced glycation endproducts. F Neural Transm 1998;105:439-61.

4 Monnier VM, Cerami A. Nonenzymatic browning in vivo: possible process for aging of long-lived proteins. Science 1981;211:491-3.

5 Sell DR, Monnier VM. End-stage renal disease and diabetes catalyze the formation of a pentose-derived crosslink from aging human collagen. $\mathcal{F}$ Clin Invest 1990;85:380-4.

6 Jiaan DB, Seftel AD, Fogarty J, et al. Age-related increase in an advanced glycation end product in penile tissue. World f Urol 1995;13:369-75.

7 Seftel AD, Vaziri ND, Ni Z, et al. Advanced glycation end products in human penis: elevation in diabetic tissue, site of deposition, and possible human penis: elevation in diabetic tissue, site of deposition,
effect through iNOS or eNOS. Urology 1997;50:1016-26.

8 Matsuse T, Ohga E, Teramoto S, et al. Immunohistochemical localisation of advanced glycation end products in pulmonary fibrosis. F Clin Pathol 1998; 51:515-9.

9 Stitt AW, Vlassara H, Bucala R. Atherogenesis and advanced glycation: promotion, progression, and prevention. In: Chiorazzi N, Fujio-Numano RG, Ross R, eds. "Atherosclerosis IV." Ann NY Acad Sci 1997; 811:115-29.

10 Stitt AW, He C, Friedman S, et al. Elevated AGE-modified ApoB in the sera of euglycemic, normolipidemic patients with atherosclerosis. Mol Med 1997;3:617-27.

11 Baynes JW, Monnier VM, eds. The Maillard reaction in aging, diabetes, and nutrition. In: Prog Clin Biol Res. New York: Alan R Liss 1989;304:1-410.

12 Maillard LC. Action des acides amines sur les sucres: formation des melanoides par voie methodique. CR Acad Sci 1912;154:66-8.

13 Patton AR, Hill EG Inactivation of nutrients by heating with glucose. Science 1948;107:68-9.

14 Takagi Y, Kashiwagi A, Tanaka Y, et al. Significance of fructose-induced protein oxidation and formation of advanced glycation endproducts. $\mathcal{F}$ Diabetes Compl 1995;9:87-91. 
15 Koenig RJ, Blobstein SH, Cerami A. Structure of carbohydrate of hemoglobin A1c. F Biol Chem 1977;252:2992-7.

16 Cerami A, Stevens VJ, Monnier VM. Role of nonenzymatic glycosylation in the development of the sequelae of diabetes mellitus. Metabolism 1979;28(Suppl 1):431-7.

17 Vishwanath V, Frank KE, Elmets CA, et al. Glycation of skin collagen in type I diabetes mellitus. Correlation with long-term complications. Diabetes 1986;35:916-21.

18 Ahmed MU, Thorpe SR, Baynes JW Identification of carboxymethyllysine as a degradation product of fructoselysine in glycated protein. $\mathcal{F}$ Biol Chem $1986 ; 261: 8816-21$.

19 Wells-Knecht MC, Thorpe SR, Baynes JW. Pathways of formation of glycoxidation

20 Thornalley PJ, Langborg A, Minhas HS. Formation of glyoxal, methylglyoxal and 3-deoxyglucosone in the glycation of proteins by glucose. Biochem O 1999;344:109-16.

21 Thornalley PJ. The glyoxalase system: new developments towards characterisation of a metabolic pathway fundamental to biological life. Biochem 71 1990;269:1-11.

22 Njoroge FG, Sayre LM, Monnier VM. Detection of D-glucose-derived pyrrole compounds during Maillard reaction under physiological conditions. Carbohydr Res 1987;167:211-20.

23 Miyata S, Monnier V. Immunohistochemical detection of advanced glycosylation end products in diabetic tissues using monoclonal antibody to pyrraline. F Clin Invest 1992;89:1102-12.

24 Obayashi $\mathrm{H}$, Nakano $\mathrm{K}$, Shigeta $\mathrm{H}$, et al. Formation of crossline as a fluorescent advanced glycation end product in vitro and in vivo. Biochem Biophys Res Coтmun 1996;226:37-41.

25 Sell DR, Nagaraj RH, Grandhee SK, et al. Pentosidine: a molecular marker for the cumulative damage to proteins in diabetes, aging, and uremia. Diabetes Metab Rev 1991;7:239-51.

26 Portero-Otin M, Pamplona R, Bellmunt MJ, et al. Urinary pyrraline as a biochemical marker of non-oxidative Maillard reactions in vivo. Life Sci 1997;60:279-87.

27 Cerami C, Founds H, Nicholl I et al. Tobacco smoke is a source of toxic reactive glycation products. Proc Natl Acad Sci USA 1997;94:13915-20.

28 Nicholl ID, Stitt AW, Moore JE, et al. Increased levels of advanced glycation endproducts in the lenses and blood vessels of cigarette smokers. Mol Med 1998;4:594-601.

29 Koschinsky T, He CJ, Mitsuhashi T, et al. Orally absorbed reactive glycation products (glycotoxins): an environmental risk factor in diabetic nephropathy. Proc Natl Acad Sci USA 1997; 94:6474-9.

$30 \mathrm{He}$ C, Sabol J, Mitsuhashi T, et al. Dietary glycotoxins: inhibition of reactive products by aminoguanidine facilitates renal clearance and reduces tissue sequestration. Diabetes 1999;48:1308-15.

31 Schmidt AM, Hori O, Brett J, et al. Cellular receptors for advanced glycation end products. Implications for induction of oxidant stress and cellular dysfunction in the pathogenesis of vascular lesions. Arterioscler Thromb 1994;14:1521-28.

$32 \mathrm{Li} \mathrm{YM}$, Mitsuhashi T, Wojciehowicz D, et al. Molecular identity and cellular distribution of advanced glycation endproduct receptors. Relationship of p 60 to OST-48 and $80 \mathrm{~K}-\mathrm{H}$ membrane proteins. Proc Natl Acad Sci USA 1996;93:11047-52.

33 Stitt AW, He CJ, Vlassara H. Characterization of the advanced glycation endproduct receptor complex in human vascular endothelial cells. Biochem Biophys Res Comm 1999;256:549-56.

34 Horiuchi S, Higashi T, Ikeda K, et al. Advanced glycation end products and their recognition by macrophage and macrophage-derived cells. Diabetes 1996;45(Suppl 3):S73-S76.

35 Mene P, Pascale C, Teti A, et al. Effects of advanced glycation end products on cytosolic $\mathrm{Ca} 2+$ signaling of cultured human mesangial cells. f $\mathrm{Am} S \mathrm{Soc}$ Nephrol 1999;10:1478-86.

36 Scivittaro V, Ganz MB, Weiss MF. AGEs induce oxidative stress and activate protein kinase C-beta(II) in neonatal mesangial cells. Am F Physiol Renal Physiol 2000;278:F676-83.

37 Huang JS, Guh JY, Hung WC, et al. Role of the Janus kinase (JAK)/signal transducters and activators of transcription (STAT) cascade in advanced glycation end-product-induced cellular mitogenesis in NRK- $49 \mathrm{~F}$ cells. Bioglycation end-product-induced cel
chem $71999 ; 342(\mathrm{Pt} 1): 231-8$.

38 Deora AA, Win T, Vanhaesebroeck B, et al. A redox-triggered ras-effector interaction. Recruitment of phosphatidylinositol 3'-kinase to Ras by redox stress. F Biol Chem 1998;273:29923-8.

39 Lander HM, Tauras JM, Ogiste JS, et al. Activation of the receptor for advanced glycation end products triggers a p21(ras)-dependent mitogenactivated protein kinase pathway regulated by oxidant stress. $\mathcal{F}$ Biol Chem 1997;272:17810-4.

40 Simm A, Munch G, Seif F, et al. Advanced glycation endproducts stimulate the MAP-kinase pathway in tubulus cell line LLC-PK1. FEBS Lett 1997; 410:481-4

41 Vlassara H, Fuh H, Makita Z, et al. Exogenous advanced glycosylation end products induce complex vascular dysfunction in normal animals: a model for diabetic and ageing complications. Proc Natl Acad Sci USA 1992;89:12043-7.

42 Yang CW, Vlassara H, Peten EP, et al. Advanced glycation end products up-regulate gene expression found in diabetic glomerular disease. Proc Natl up-regulate gene expression foun

43 Vlassara H, Striker LJ, Teichberg S, et al. Advanced glycation end products induce glomerular sclerosis and albuminuria in normal rats. Proc Natl Acad Sci USA 1994;91:11704-8.

44 Bucala R, Model P, Cerami A. Modification of DNA by reducing sugars: a possible mechanism for nucleic acid aging and age-related dysfunction in gene expression. Proc Natl Acad Sci USA 1984;81:105-9.

45 Ledesma MD, Bonay P, Colaco C, et al. Analysis of microtubule-associated protein tau glycation in paired helical filaments. F Biol Chem 1994;269: 21614-9.

46 Howard EW, Benton R, Ahern-Moore J, et al. Cellular contraction of collagen lattices is inhibited by nonenzymatic glycation. Exp Cell Res 1996;228: 132-7.

47 Paget C, Lecomte M, Ruggiero D, et al. Modification of enzymatic antioxidants in retinal microvascular cells by glucose or advanced glycation end dants in retinal microvascular cells by glucose
products. Free Radic Biol Med 1998;25:121-9.

48 Giardino I, Edelstein D, Brownlee M. Nonenzymatic glycosylation in vitro and in bovine endothelial cells alters basic fibroblast growth factor activity.
A model for intracellular glycosylation in diabetes. 7 Clin Invest 1994;94:110-7.

49 Abdel-Wahab YH, O'Harte FP, Ratcliff $\mathrm{H}$, et al. Glycation of insulin in the islets of Langerhans of normal and diabetic animals. Diabetes 1996;45: $1489-96$.

50 World Health Organization. Stragegies for the prevention of blindness in national programmes. Geneva: WHO, 1997:68.

51 Delcourt C, Cristol JP, Tessier F, et al. Risk factors for cortical, nuclear, and posterior subcapsular cataracts: the POLA study. Pathologies Oculaires Liees a l'Age. Am F Epidemiol 2000;151:497-504.

52 Taylor HR. Epidemiology of age-related cataract. Eye 1999;13:445-8.

53 Garner B, Davies MJ, Truscott RJ. Formation of hydroxyl radicals in the human lens is related to the severity of nuclear cataract. Exp Eye Res 2000; $70 \cdot 81-8$

54 Dillon J. UV-B as a pro-aging and pro-cataract factor. Doc Ophthalmol 1994; 88:339-44.

55 Harding JJ, Crabbe MJC. In: Davson H, ed. The lens: development proteins, metabolism and cataract. The eye. Vol 1b. New York: Academic Press, 1984: 207-492.

56 Stevens VJ, Rouzer CA, Monnier VM, et al. Diabetic cataract formation: potential role of glycosylation of lens crystallins. Proc Natl Acad Sci USA 1978;75:2918-22.

57 Monnier VM, Stevens VJ, Cerami A. The browning reaction of proteins with glucose. Arch Biochem 1979;24:157-78.

58 Matsumoto K, Ikeda K, Horiuchi S, et al. Immunochemical evidence for increased formation of advanced glycation end products and inhibition by aminoguanidine in diabetic rat lenses. Biochem Biophys Res Coтmun 1997; 241:352-4.

59 Bron AJ, Vrensen GF, Koretz J, et al. The ageing lens. Ophthalmologica 2000;214:86-104

60 Farrukh AS, Sharkey E, Creighton D, et al. Maillard reactions in lens proteins: methylglyoxal-mediated modifications in the rat lens. Exp Eye Res 2000;70:369-80

61 Chellan P, Nagaraj RH. Protein crosslinking by the Maillard reaction: dicarbonyl-derived imidazolium crosslinks in aging and diabetes. Arch Biochem Biophys 1999;368:98-104.

62 Derham BK, Harding JJ. Alpha-crystallin as a molecular chaperone. Prog Retin Eye Res 1999;18:463-509.

63 Awasthi YC, Miller SP, Arya DV, et al. The effect of copper on human and bovine lens and on human cultured lens epithelium enzymes. Exp Eye Res 1975;21:251-7

64 Lin J. Pathophysiology of cataracts: copper ion and peroxidation in diabetics. Эpn $f$ Ophthalmol 1997;41:130-7.

65 Saxena P, Saxena AK, Cui XL, et al. Transition metal-catalyzed oxidation of ascorbate in human cataract extracts: possible role of advanced glycation end products. Invest Ophthalmol Vis Sci 2000;41:1473-81.

66 Frei B, Forte TM, Ames BN, et al. Gas phase oxidants of cigarette smoke induce lipid peroxidation and changes in lipoprotein properties in human blood plasma. Protective effects of ascorbic acid. Biochem f 1991;277:1338.

67 Christen WG, Manson JE, Seddon JM, et al. A prospective study of cigarette smoking and risk of cataract in men. $\mathscr{f} A M A$ 1992;268:989-93.

68 Schultz RO, Van Horn DL, Peters MA, et al. Diabetic keratopathy. Trans Am Ophthalmol Soc 1981;79:180-99.

69 Sady C, Khosrof S, Nagaraj R. Advanced Maillard reaction and crosslinking of corneal collagen in diabetes. Biochem Biophys Res Commun 1995;214:

$70 \mathrm{Kaji}$ Y, Usui T, Oshika T, et al. Advanced glycation end products in diabetic corneas. Invest Ophthalmol Vis Sci 2000;41:362-8.

71 Malik NS, Moss SJ, Ahmed N, et al. Ageing of the human corneal stroma: structural and biochemical changes. Biochim Biophys Acta 1992;1138:2228.

72 Malik NS, Meek KM. The inhibition of sugar-induced structural alterations in collagen by aspirin and other compounds. Biochem Biophys Res Commun 1994;199:683-6.

73 Malik NS, Meek KM. Vitamins and analgesics in the prevention of collagen ageing. Age Ageing 1996:25:279-84.

74 Spoerl E, Seiler T. Techniques for stiffening the cornea. F Refract Surg 1999; 15:711-3.

75 Bishop PN. Structural macromolecules and supramolecular organisation of the vitreous gel. Prog Retin Eye Res 2000;19:323-44.

76 Sebag J, Buckingham B, Charles MA, et al. Biochemical abnormalities in vitreous of humans with proliferative diabetic retinopathy. Arch Ophthalmol 1992;110:1472-6.

77 Sebag J. Diabetic vitreopathy. Ophthalmology 1996;103:205-6.

78 Stitt AW, Moore J, Sharkey JA, et al. Advanced glycation endproducts in vitreous: structural and functional implications for diabetic vitreopathy. Invest Ophthalmol Vis Sci 1998;39:2517-23.

79 Sebag J. Abnormalities of human vitreous structure in diabetes. Graefes Arch Clin Exp Ophthalmol 1987; 225:89-93.

80 Archer DB. Bowman Lecture 1998. Diabetic retinopathy: some cellular, molecular and therapeutic considerations. Eye 1999;13:497-523.

81 Stitt AW, Li YM, Gardiner TA, et al. Advanced glycation endproducts (AGEs) co-localise with AGE-receptors in the retinal vasculature of diabetic and AGE-infused rats. Am F Pathol 1997;150:523-32.

82 Brownlee M, Cerami A, Vlassara H. Advanced glycosylation end products in tissue and the biochemical basis of diabetic complications. N Engl F Med 1988:318:1315-2

83 Hammes HP, Alt A, Niwa T, et al. Differential accumulation of advanced glycation end products in the course of diabetic retinopathy. Diabetologia 1999;42:728-36

84 Schalkwijk CG, Ligtvoet N, et al. Amadori albumin in type 1 diabetic patients: correlation with markers of endothelial function, association with
diabetic nephropathy, and localization in retinal capillaries. Diabetes 1999; 48:2446-53.

85 Murata T, Nagai R, Ishibashi T, et al. The relationship between accumulation of advanced glycation end products and expression of vascular endother

86 Hammes HP, Wellensiek B, Kloting I, et al. The relationship of glycaemic level to advanced glycation end-product (AGE) accumulation and retinal level to advanced glycation end-product (AGE) accumulation and retinal
pathology in the spontaneous diabetic hamster. Diabetologia 1998;41:165170 . 
87 Clements RS Jr, Robison WG Jr, Cohen MP. Anti-glycated albumin therapy ameliorates early retinal microvascular pathology in $\mathrm{db} / \mathrm{db}$ mice. $\mathcal{F}$ Diabetes Comp 1998,12:28-33.

88 Hammes HP, Martin S, Federlin K, et al. Aminoguanidine treatment inhibits the development of experimental diabetic retinopathy. Proc Natl Acad Sci USA 1991;88:11555-8.

89 Hammes HP, Ali SS, Uhlmann M, et al. Aminoguanidine does not inhibit the initial phase of experimental diabetic retinopathy in rats. Diabetologia 1995;38:269-73.

90 Hammes HP, Strodter D, Weiss A, et al. Secondary intervention with aminoguanidine retards the progression of diabetic retinopathy in the rat model. Diabetologia 1995;38:656-60.

91 Stitt AW, Bhaduri T, McMullen CBT, et al. Advanced glycation endproducts cause breakdown of the blood retinal barrier in normoglycaemic rats: implications for barrier discruption during diabetic retinopathy. Mol Cell Biol Res Commun 2000;3:380-8.

92 Ono Y, Aoki S, Ohnishi K, et al. Increased serum levels of advanced glycation end-products and diabetic complications. Diabetes Res Clin Pract 1998; 41:131-7.

93 Chiarelli F, de Martino M, Mezzetti A, et al. Advanced glycation end products in children and adolescents with diabetes: relation to glycemic control
and early microvascular complications. $\mathcal{F}$ Pediatr 1999;134:486-91.

94 Chakravarthy U, Hayes RG, Stitt AW, et al. Constitutive nitric oxide synthase expression in retinal vascular endothelial cells is suppressed by high glucose and advanced glycation end products. Diabetes 1998;47:94552 .

95 Yamagishi S, Fujimori $\mathrm{H}$, Yonekura $\mathrm{H}$, et al. Advanced glycation endproducts accelerate calcification in microvascular pericytes. Biochem Biophys Res Comm 1999;258:353-7.

96 Ruggiero-Lopez D, Rellier N, Lecomte M, et al. Growth modulation of retinal microvascular cells by early and advanced glycation products. Diabetes Res Clin Pract 1997;34:135-42.

97 Chibber R, Molinatti PA, Rosatto N, et al. Toxic action of advanced glycation end products on cultured retinal capillary pericytes and endothelial cells: relevance to diabetic retinopathy. Diabetologia 1997;40:156-64.

$98 \mathrm{Lu} \mathrm{M}$, Kuroki M, Amano S, et al. Advanced glycation end products increase retinal vascular endothelial growth factor expression. $\mathcal{F}$ Clin Invest 1998;101:1219-24.

99 Hirata C, Nakano K, Nakamura N, et al. Advanced glycation end products induce expression of vascular endothelial growth factor by retinal Muller induce expression of vascular endothelial growth factor
cells. Biochem Biophys Res Commun 1997;236:712-15.

100 Yamaguishi Si, Yonekura H, Yamamoto Y, et al. Advanced glycation end products-driven angiogenesis in vitro. Induction of the growth and tube formation of human microvascular endothelial cells through autocrine vascular endothelial growth factor. F Biol Chem 1997;272:8723-30.

101 Moore DJ, Hussain AA, Marshall J. Age-related variation in the hydraulic conductivity of Bruch's membrane. Invest Ophthalmol Vis Sci 1995;36: 1290-7

102 Sarks JP, Sarks SH, Killingsworth MC. Evolution of soft drusen in age-related macular degeneration. Eye 1994;8:269-83.

103 Mullins RF, Hageman GS. Human ocular drusen possess novel core domains with a distinct carbohydrate composition. F Histochem Cytochem 1999;47:1533-40.

104 Boulton M, Marshall J. Effects of increasing numbers of phagocytic inclusions on human retinal pigment epithelial cells in culture: a model for aging. Br f Ophthalmol 1986;70:808-15.

105 Pauleikhoff D, Barondes MJ, Minassian D, et al. Drusen as risk factors in age-related macular disease. Am $\mathcal{F}$ Ophthalmol 1990;109:38-43.

106 Boulton M, Moriarty P, Jarvis-Evans J, et al. Regional variation and age-related changes of lysosomal enzymes in the human retinal pigment epithelium. Br Ophthalmol 1994;78:125-9.

107 Rakoczy PE, Baines M, Kennedy CJ, et al. Correlation between autofluorescent debris accumulation and the presence of partially processed forms of cathepsin D in cultured retinal pigment epithelial cells challenged with rod outer segments. Exp Eye Res 1996;63:159-67.

108 Ishibashi T, Sorgente N, Patterson R, et al. Pathogenesis of drusen in the primate. Invest Ophthalmol Vis Sci 1986;27:184-93.

109 Feeney-Burns L, Gao CL, Tidwell M. Lysosomal enzyme cytochemistry of human RPE, Bruch's membrane and drusen. Invest Ophthalmol Vis Sci 1987;28:1138-47.

110 Hammes HP, Hoerauf H, Alt A, et al. N(epsilon)(carboxymethyl)lysin and the AGE receptor RAGE colocalize in age-related macular degeneration. Invest Ophthalmol Vis Sci 1999;40:1855-9.

111 Handa JT, Verzijl N, Matsunaga H, et al. Increase in the advanced glycation end product pentosidine in Bruch's membrane with age. Invest Ophthalmol Vis Sci 1999;40:775-9.

112 Handa JT, Reiser KM, Matsunaga $\mathrm{H}$, et al. The advanced glycation endproduct pentosidine induces the expression of PDGF-B in human retiendproduct pentosidine induces the expression of PDGF-1

113 Farboud B, Aotaki-Keen A, Miyata T, et al. Development of a polyclonal antibody with broad epitope specificity for advanced glycation endproducts and localization of these epitopes in Bruch's membrane of the aging eye. Mol Vis 1999;14:5-11.

114 Hageman GS, Mullins RF, Russell SR, et al. Vitronectin is a constituent of ocular drusen and the vitronectin gene is expressed in human retinal pigmented epithelial cells. FASEB f 1999;13:477-84
115 Mullins RF, Russell SR, Anderson DH, et al. Drusen associated with aging and age-related macular degeneration contain proteins common to extracellular deposits associated with atherosclerosis, elastosis, amyloidosis, and dense deposit disease. FASEB F 2000;14:835-46.

$116 \mathrm{Li}$ YM, Dickson DW. Enhanced binding of advanced glycation endproducts (AGE) by the ApoE4 isoform links the mechanism of plaque deposition in Alzheimer's disease. Neurosci Lett 1997;226:155-8.

117 Tabaton M, Perry G, Smith M, et al. Is amyloid beta-protein glycated in Alzheimer's disease? Neuroreport 1997;8:907-9.

118 Hammes HP, Weiss A, Hess S, et al. Modification of vitronectin by advanced glycation alters functional properties in vitro and in the diabetic retina. Lab Invest 1996;75:325-38

119 Okubo A, Rosa RH Jr, Bunce CV, et al. The relationships of age changes in retinal pigment epithelium and Bruch's membrane. Invest Ophthalmol Vis Sci 1999;40:443-9.

120 Kasper M, Schinzel R, Niwa T, et al. Experimental induction of AGEs in fetal L132 lung cells changes the level of intracellular cathepsin D. Biochem Biophys Res Commun 1999;261:175-82.

121 Sebekova K, Schinzel R, Ling H, et al. Advanced glycated albumin impairs protein degradation in the kidney proximal tubules cell line LLC-PK1. Cell Mol Biol (Noisy-le-grand) 1998;44:1051-60.

122 Miyata S, Liu BF, Shoda H, et al. Accumulation of pyrraline-modified albumin in phagocytes due to reduced degradation by lysosomal enzymes. f Biol Chem 1997;272:4037-42.

123 Boulton M, McKechnie NM, Breda J, et al. The formation of autofluorescent granules in cultured human RPE. Invest Ophthalmol Vis Sci 1989;30:82-9.

124 Yin D. Biochemical basis of lipofuscin, ceroid, and age pigment-like fluorophores. Free Radic Biol Med 1996;21:871-88

125 Leske MC. The epidemiology of open-angle glaucoma: a review. Am f Epidemiol 1983;118:166-91.

126 Albon J, Karwatowski WS, Avery N, et al. Changes in the collagenous matrix of the aging human lamina cribrosa. Br f Ophthalmol 1995;79:36875 .

127 Ino-ue M, Ohgiya N, Yamamoto M. Effect of aminoguanidine on optic nerve involvement in experimental diabetic rats. Brain Res 1998;800:31922.

128 Brownlee M, Vlassara H, Kooney A, et al. Aminoguanidine prevents diabetes-induced arterial wall protein cross-linking. Science 1986;232: 1629-32.

129 Panagiotopoulos S, O'Brien RC, Bucala R, et al. Aminoguanidine has an anti-atherogenic effect in the cholesterol-fed rabbit. Atherosclerosis 1998; 136:125-31.

130 Ido Y, Chang K, Ostrow E, et al. Aminoguanidine prevents regional blood flow increases in streptozotocin-diabetic rats. Diabetes 1990;39:93A.

131 Soulis Liparota T, Cooper M, Papazoglou D, et al. Retardation by aminoguanidine of development of albuminuria, mesangial expansion, and tissue fluorescence in streptozotocin induced rat. Diabetes 1991;40:1328-34.

132 Edelstein D, Brownlee M. Mechanistic studies of advanced glycosylation endproduct inhibition by aminoguanidine. Diabetes 1992;41:26-8.

133 Cho HK, Kozu H, Peyman GA, et al. The effect of aminoguanidine on the blood retinal barrier in streptozotocin induced diabetic rats. Ophthalmic Surg 1991;22:44-7.

134 Bucala R, Vlassara $\mathrm{H}$. Advanced glycosylation end products in diabetic renal and vascular disease. Am F Kidney Dis 1995;26:875-88.

135 Jianmongkol S, Vuletich JL, Bender AT, et al. Aminoguanidine-mediated inactivation and alteration of neuronal nitric-oxide synthase. 7 Biol Chem 2000;275:13370-6.

136 Nakamura S, Makita Z, Ishikawa S, et al. Progression of nephropathy in spontaneous diabetic rats is prevented by OPB-9195, a novel inhibitor of advanced glycation. Diabetes 1997;46:895-9.

137 Onorato JM, Jenkins AJ, Thorpe SR, et al. Pyridoxamine, an inhibitor of advanced glycation reactions, also inhibits advanced lipoxidation reactions: mechanism of action of pyridoxamine. F Biol Chem 2000;275:13370-6.

138 Soulis T, Sastra S, Thallas V, et al. A novel inhibitor of advanced glycation end-product formation inhibits mesenteric vascular hypertrophy in experimental diabetes. Diabetologia 1999;42:472-9.

139 Mitsuhashi T, Li YM, Fishbane S, et al. Depletion of reactive advanced glycation endproducts from diabetic uremic sera using a lysozyme-linked matrix. F Clin Invest 1997;100:847-54.

140 Vasan S, Zhang X, Zhang X, et al. An agent cleaving glucose-derived protein crosslinks in vitro and in vivo. Nature 1996;382:275-8.

141 Cooper ME, Thallas V, Forbes J, et al. The cross-link breaker, $\mathrm{N}$-phenacylthiazolium bromide prevents vascular advanced glycation endproduct accumulation. Diabetologia 2000;43:660-4.

142 Wolffenbuttel BH, Boulanger CM, Crijns FR, et al. Breakers of advanced glycation end products restore large artery properties in experimental diabetes. Proc Natl Acad Sci USA 1998;95:4630-4.

143 Asif M, Egan J, Vasan S, et al. An advanced glycation endproduct cross-link breaker can reverse age-related increases in myocardial stiffness. Proc Natl Acad Sci USA 2000;97:2809-13. 